Australia, Austria, Belgium, Benin, Botswana, Brazil, Bulgaria, Burundi, Byelorussia, Canada, Cape Verde, China, Colombia, Congo, Cuba, Cyprus, Czechoslovakia, Denmark, Egypt, Ethiopia, Fiji, Finland, France, German Democratic Republic, Federal Republic of Germany, Ghana, Greece, Guinea, Guinea-Bissau, Guyana, Haiti, Hungary, India, Indonesia, Iran, Iraq, Italy, Ivory Coast, Jamaica, Japan, Kenya, Lesotho, Liberia, Libya, Madagascar, Malawi, Malaysia, Mail, Mauritania, Mauritius, Mexico, Mongolia, Mozambique, Netherlands, Niger, Nigeria, Norway, Pakistan, Panama, Peru, Philippines, Poland, Portugal, Romania, Sao Tome and Principe, Senegal, Sierra Leone, Somalia, Spain, Sri Lanka, Sudan, Swaziland, Sweden, Syria, Togo, Trinidad and Tobago, Tunisia, Turkey, Uganda, Ukraine, USSR, United Arab Emirates, United Kingdom, United Republic of Tanzania, United States, Venezuela, Yugoslavia, Zaire, and Zambia.

Some 107 representatives of the international news media were accredited to cover the Conference, along with 47 representatives of local media.

United Nations Office of Public Information

Press Section

New York, New York

24 May 1977

\title{
LETTER/MOZAMBIQUE EDUCATIONAL FUND
}

June 22, 1977

Dear Africanists:

Accompanying this letter is a letter from the Mozambican Minister of Education, Graca Simbine, in which she describes the serious problems Mozambique inherited as a result of 400 years of Portuguese colonial rule. Lisbon's conscious denial of educational opportunities to the masses of Mozambicans meant that at the time of independence the rate of illiteracy was estimated at over $95 \%$.

In sharp contrast to the colonial regime, FRELIMO, from the outset of the struggle, placed the highest priority on education. In the liberated zones schools were quickly established and the problems of illiteracy and Portuguese cultural imperialism attacked. Since independence this campaign has been intensified in an effort to create a new consciousness and a just society. The extent to which FRELIMO has been successful is reflected in the dramatic increase in the number of students enrolied in classes. Whereas in 1973 only 700,000 Mozambicans had any access to education, now more than two million are attending school. In short, the Mozambican government has gone to great length to make educational opportunities accessible to all its citizens-young and old, male and female, workers and peasants.

These gains have been made despite the acute shortage of books, maps, and other educational materials. While working along the Zimbabwean border this summer, it was not uncommon for us to visit schools which lacked books, paper, pencils, chalk and other essentials. Mozambican officials acknowledged that similar problems existed throughout the country. To complicate matters, they pointed out that most of the educational material inherited from the colonial period was useless and much of it had to be destroyed. In an effort to overcome the shortage of books, teachers often have to stay up until the early hours of the morning preparing material to be used in their classes the following day.

Upon returning to Maputo we had several discussions with Mozambican officials including the Vice President, about the formation of a North-American based fund which would collect donations from progressive Africanists, Southern African activists and other individuals and groups sympathetic to Mozambique. In subsequent discussions with people in the Ministry of Education, it was agreed that the Mozambique Educational Fund would purchase books primarily in Portugal and Brazil, and arrange for their overseas shipment. This enlargement of our task was necessitated by acute labor shortages within the Ministry of Education.

At the moment we are contacting about fifty individuals who are both visible and committed, asking them to contribute generously and to publicly endorse the Mozambique Education Fund. We hope that you will agree to participate and allow your name to be listed on the letterhead. All letters of endorsement and checks should be sent to:

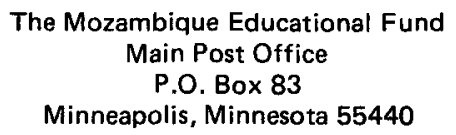


We expect to receive firm responses within a month and then will decide whether to send out a national mailing of several thousand before the end of the academic year or wait until September. In the interim we will try to get as many different mailing lists as possible and buy a limited number of books with the first round of contributions. (We are currently applying for tax exempt status). This summer we will be in Mozambique and will collect new curriculum and reading lists as they are developed by the Ministry of Education.

With best wishes and fraternal greetings Allen I saacman

Professor, Department of History and Afro-American Studies

Associate, Centro de Estudos Africanos, Universidade de Eduardo Mondlane

Barbara Isaacman Attorney

Sometime Associate, Centro de Estudos Africanos, Universidade de Eduardo Mondlane

\section{Dear Mr. Isaacman,}

Thank you for your recent letter informing us about the establishment of the Mozambique Educational Fund.

As you are aware, Portuguese colonialism left Mozambique with very acute economic and social problems. However, during the first year of independence, the government of the People's Republic of Mozambique began to tackle some of the most glaring sources of inequality and injustice and to lay foundations for a new society.

However the end of the exploitation, the formation of a new mentality, new relations between men, and the creation of a just economic infrastructure, do not occur overnight. Only with time will it be possible to put science and technology in the hands of the working people so that they can build the development that truly serves their own interests.

It is our task in education to ensure that all this is achieved as rapidly and effectively as possible.

Although one of our guiding principles has always been, and will continue to be, the necessity for self-reliance, "depender das nossas proprias forcas" nevertheless we always welcome outside external support for our efforts, when based on genuine internationalist principles of solidarity between peoples.

For this reason we welcome the enterprising initiative taken by you and your colleagues in establishing the Mozambique Educational Fund and wish you success in your venture.

Ministry of Education and Culture, Maputo, 21 st December 1976.

Graca Simbine

\section{LETTER/WORLD CONGRESS OF SOCIOLOGY}

Dear Colleague:

We have been invited to co-chair the section on Language Planning and Socioeconomic Development at the IXth World Congress of Sociology to be held at Upsalla, Sweden in August of 1978, and we should appreciate your help in locating persons who may be interested in participating in any of the activities of this section.

While the main responsibility of the section will be the formal presentation of four position papers on the state of the art, we shall also be concerned with organizing more informal sessions such as roundtables, workshops, lunch groups, and so forth to exchange information on work in progress and to map out areas of research that need additional effort. What we need now are: (1) detailed proposals for the main position papers; (2) suggestions for themes for the informal meetings along with recommendations concerning the specific structure of such meetings; (3) and, names and 